TAO, Vol.6, No.1, 1-11, March 1995

\title{
Kuroshio Meandering and Eddy Formation to the East of Taiwan and Their Reflection in Potassium Fields
}

\author{
VICTOR K. SAVCHENKo, ${ }^{1}$ ALEXANDER S. BYCHKOV ${ }^{1}$ and VICTOR I. ILYICHEV ${ }^{1}$
}

(Manuscript received 30 April 1994, in final form 16 December 1994)

\begin{abstract}
CTD data collected during the KEEP-MASS expedition on the $R / V$ "Akademik Alexandr Vinogradov" (ROC-Russia Marine Science Collaboration Project, cruise V23/KM92, July, 1992) were used for dynamic calculations of the currents observed to the east of Taiwan Island. Water circulation in the study area was analyzed on the basis of the surface chart of dynamic topography and distributions of meridianal and zonal components of current velocity fields. Based on the dynamic topography chart in the area to the east of Taiwan, the Kuroshio current is represented by two branches. One narrow branch runs along the eastern coast and forms a number of eddies when turning into the Okinawa Trough. Another branch separates from the coastal one near Lanhsu Island and generates anticyclonic and cyclonic meanders to the south-east of Taiwan. This circulation schematic is indirectly supported by the characteristics of potassium and the $\mathrm{K} / \mathrm{Cl}$ ratio distribution.
\end{abstract}

(Key words: Kuroshio, Meandering, Potassium)

\section{INTRODUCTION}

Scientific literature presented in a number of papers deals with problems of the Kuroshio current meandering and eddy formations, but most of it discusses the processes observed in the frontal zone of the Kuroshio-Oyashio system or the area to the south of Japan (Masuzawa, 1955, 1957; Ichiye, 1955; Ichiye and Ichiye, 1956; Kawai, 1972; Kitano, 1975; Cheney, 1977; Nishiyama et al., 1980; Sugimoto et al., 1988; Qiu et al.,1990). The main aspects of seawater circulation and characteristics of hydrographic conditions around Taiwan are published elsewhere (Nitani, 1972; Fan, 1979, 1980, 1982, 1984; Fan and Yu, 1981; Chem et al., 1990; Hsueh et al., 1992; Chuang et al., 1993). However, until now the meandering at the beginning of the Kuroshio to the east of Taiwan has not been a subject of regular concern study steady consideration. The papers that are available describe this part of the Kuroshio as a strong flow running north-east along the eastern coast of the island into the East China Sea. The hypothesis on the Kuroshio meandering in the region under study first arose

1 Pacific Oceanological Institute, Far Eastern Branch, Russian Academy of Sciences, Vladivostok, 690041, Russia 
from the analysis of potassium distribution along $22^{\circ} \mathrm{N}$ which revealed alternated isolated pools. A similar distribution had been already found near the equator in the Indian Ocean (Savchenko et al., 1988), where isolated potassium pools corresponded to locations of jet-like equatorial currents. This similarity suggested the existence of alternate jets which could be conditioned either by the Kuroshio meandering or eddy formations.

To test the above hypothesis, dynamic calculations were realized using CTD data. Water circulation to the east of Taiwan obtained with the dynamic method and potassium and $\mathrm{K} / \mathrm{Cl}$ ratio distribution associated with this circulation are discussed in this paper.

\section{METHODS AND MATERIALS}

Dynamic calculations of oceanic currents were perforned using temperature and salinity data collected with Guildline CTD (model 875) during the KEEP-MASS expedition on $R / V$ "Akademik Alexandr Vinogradov" (ROC-Russia Marine Science Collaboration Project, cruise V23/KM92) in July, 1992 (Chen and Bychkov, 1992). A latitudinal section along $22^{\circ} \mathrm{N}$ and a longitudinal one along $122^{\circ} \mathrm{E}$ were chosen in order to cross the supposed Kuroshio track twice.

Sea water circulation in the region under study is discussed with the aid of dynamic topography charts and the distribution of the meridional and zonal components of the geostrophic currents for the transects mentioned above. The isobaric surface of $1,600 \mathrm{db}$ was used as the true zero height for the chart of dynamic topography (Figure 1). This choice was based on the analysis performed for stations 6-11 using the method of equal differences of dynamic heights (Defant, 1961). Owing to the noticable variations in bottom depths, all dynamic heights were calculated relative to station 6 . It should be mentioned that for dynamic estimations along the transects (Figures 2 and 3), seafloor relief was taken into account. Calculations based on two different zero surfaces gave the same geostrophic currents.

Constructing dynamic topography charts, the authors had some problems with the representation of the current fields. At first sight, the data of two transects, longitudinal and latitudinal, seemed to be too insufficient to produce the chart of dynamic topography. However, with the transects being located practically perpendicular to each other, an attempt to draw dynamic horizontals was made. This helped to reveal a flow running along the Taiwanese coast which corresponded to the location of the Kuroshio current. The position of dynamic horizontals coincident with the Kuroshio track were assumed to be the third section with equal dynamic heights. The dynamic topography chart was drawn for the area within a triangular shape fonned by this section together with the longitudinal and latitudinal transects.

Seawater was taken with 10-liter PVC Niskin-type bottles, and all analyses were accomplished on a shipboard. Salinity samples were collected and stored following WOCE recommendations (Stalcup, 1991). Measurements were carried out on the Guildline Autosal (model 8400) with the salinometer was standardized daily with IAPSO standard seawater. The potentiometric method described by Midgley and Torrance (1978) and modified by Isaeva et al. (1986) was applied for potassium determination. The precision estimated from the analyses of replicates was $\pm 0.1 \%$.

\section{RESULTS AND DISCUSSION}

The surface chart of dynamic topography (Figure 1) demonstrates the following circulation pattern. Near the southern extreme of Taiwan, the current is divided into two branches: 


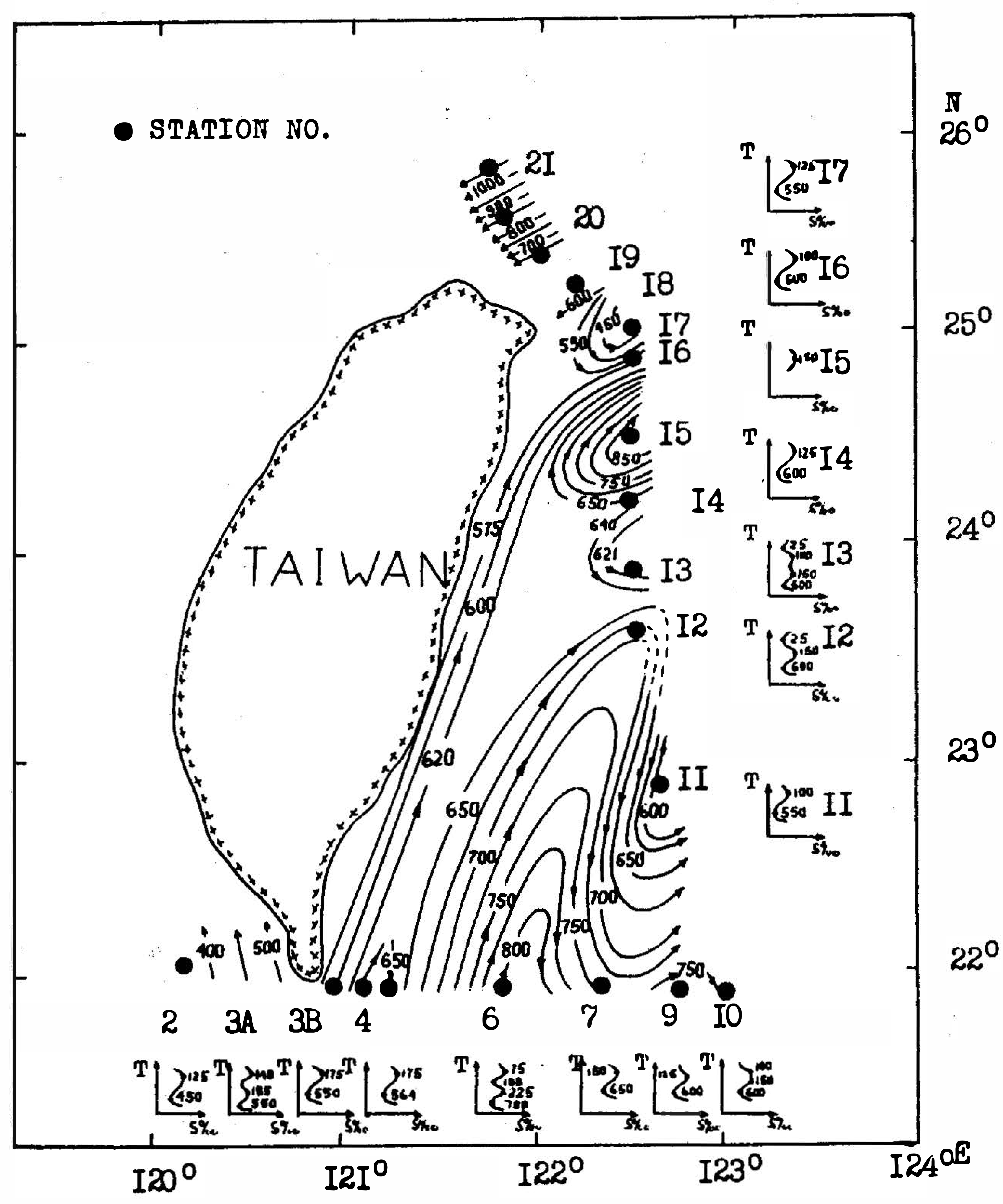

Fig. 1. The chart of dynamic topography at a $5 \mathrm{~m}$ depth east off Taiwan (the isobaric surface of $1600 \mathrm{db}$ was chosen as the true zero height). T,S - diagrams for individual stations are shown inside the margins.

one having a velocity of about $20 \mathrm{~cm} / \mathrm{sec}$ directed towards the Taiwan Strait and the other having a velocity of about $90 \mathrm{~cm} / \mathrm{sec}$ east along and off of eastern Taiwan.

To the east of Taiwan (within the area bounded by the $22^{\circ} \mathrm{N}$ and $122^{\circ} \mathrm{E}$ sections) two streams stand out, based on their T,S- characteristics, and they could be classified as the structure of the Kuroshio. One narrow branch flows north-west along the eastern coast of the island with a velocity of $90 \sim 150 \mathrm{~cm} / \mathrm{sec}$. It creates a number of eddy formations when turning into the Okinawa Trough near stations 15-16. The characteristic feature of these eddies is their occurrence in the vicinity of the Nansei Isles with an anticyclonic eddy directly above the rise and cyclonic eddies along both sides of the seamount. This is the reason for considering the mentioned formations topographic eddies. The theoretical basis for the possibility of eddy formation for currents flowing over topographic features was worked out by Huppert and Bryan (1976). 


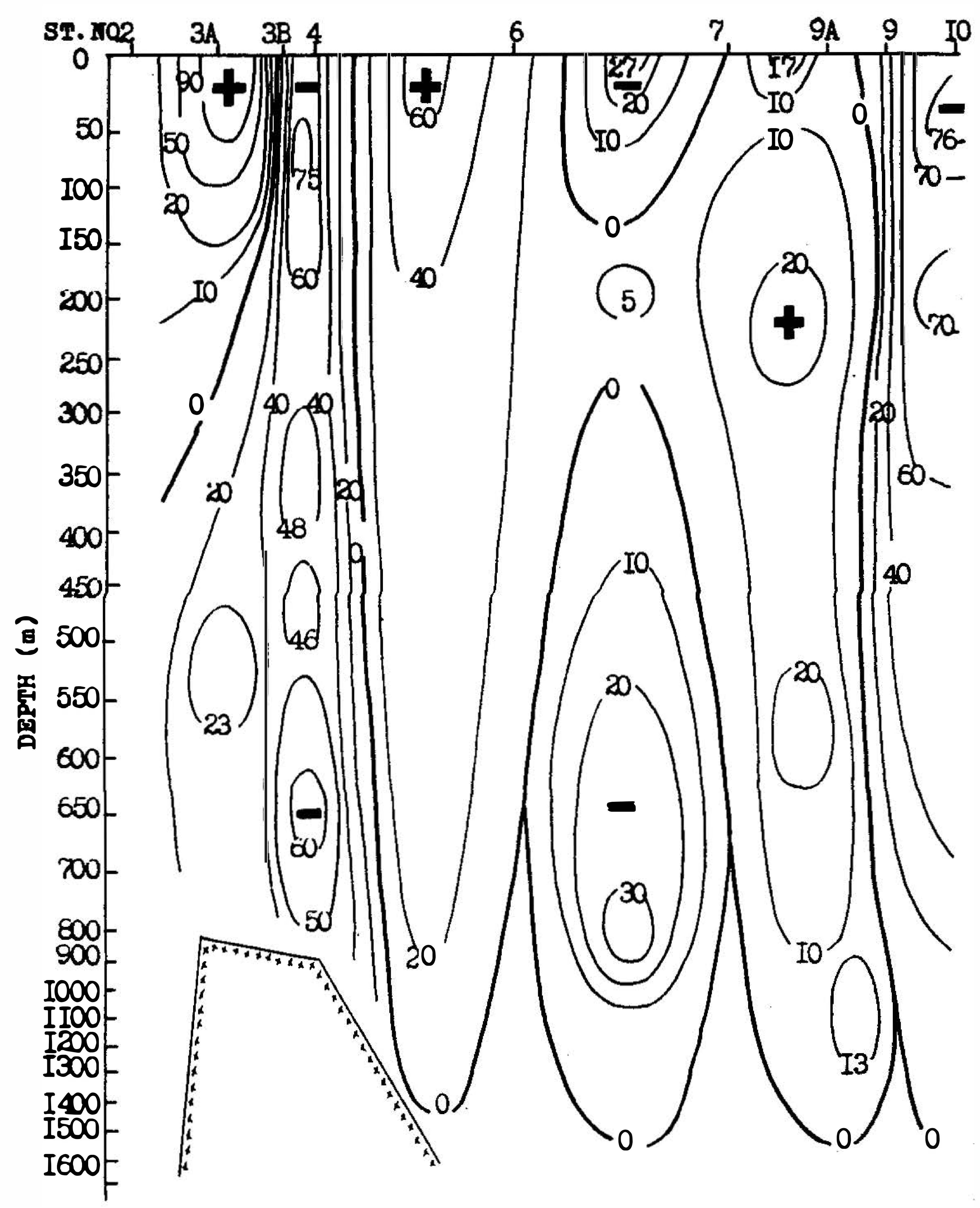

Fig. 2. The vertical distribution of the velocity of currents $(\mathrm{cm} / \mathrm{sec})$ along $22^{\circ} \mathrm{N}$ based on dynamic calculations (signs " + " and "-" show northward and southward flows, respectively).

The other branch separates from the coastal one near Lanhsu Island and forms anticyclonic and cyclonic meanders to the south-east of Taiwan. Water mass analyses showed that meandering and eddy formations in the area of the Nansei Isles contained the the undersurface maximum and intermediate minimum of the salinity characteristic of tropical water structure.This conclusion is supported by T.S diagram. (Figure 1). Distribution of the meridional and zonal components of the geostrophic currents for the sections along $22^{\circ} \mathrm{N}$ (Figure 2) and $122^{\circ} \mathrm{E}$ (Figure 3 ) reveals cores of currents alternating in sign.

On the western side of the anticyclonic meander between stations 4 and 6 , the velocity reached $60 \mathrm{~cm} / \mathrm{sec}$; on the eastern side between stations 6 and 7, it was $20-30 \mathrm{~cm} / \mathrm{sec}$ (Figure 2). It was also discovered that between stations 6 and 7 at the depth of 120 250 $\mathrm{m}$, the southward stream of the anticyclonic meander was interrupted by a weak northward undercurrent $(5 \mathrm{~cm} / \mathrm{sec})$. In the cyclonic meander in the inflow region between stations 9 and 10 the stream velocity increased again up to $70 \mathrm{~cm} / \mathrm{sec}$ (Figure 2). Along the quazimeridional 


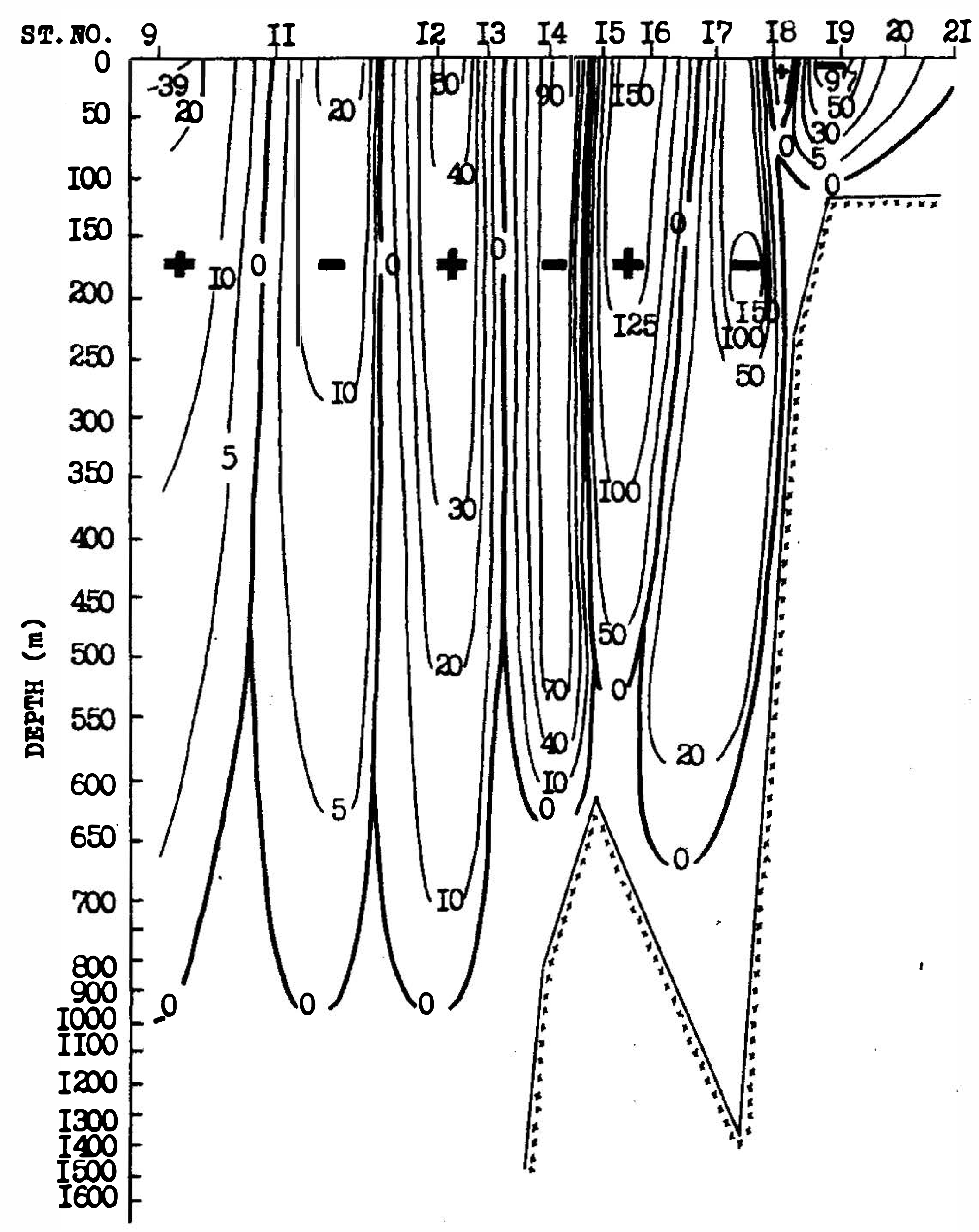

Fig. 3. The vertical distribution of the velocity of currents $(\mathrm{cm} / \mathrm{sec})$ along $122^{\circ} \mathrm{E}$ based on dynamic calculations (sings " + " and "-" show northward and southward flows, respectively).

section (Figure 3) the highest velocities (up to $150 \mathrm{~cm} / \mathrm{sec}$ ) were registered in the area of eddy-formations between stations 14-18. The average velocity within the eddies proper was about $90 \mathrm{~cm} / \mathrm{sec}$.

It is interesting to compare the composed chart of surface circulation around Taiwan (Figure 1) with the existing one (Figure 4). The newer version reproduces the main features developed by Stommel and Ioshida (taken from Fan, 1984). At the same time it points out the dependence of water circulation upon the seafloor topography by adding some missing details, namely, the meandering of the Kuroshio to the south-east of Taiwan and the eddyfonnations in the area of the Nansei Rise. Dynamic calculations generally produce results which are considered reliable regarding water circulation if they agree with the distributions of the hydrological and hydrochemical properties. In this paper, potassium characteristics ( $K$ and the $\mathrm{K} / \mathrm{Cl}$ ratio), not wide-spread in oceanological investigations until now, were used as tracers of water movement. The data given in Figures 5 and 6 indicate that the potassium distribution indirectly reflects the water circulation features in the area under study. In the 


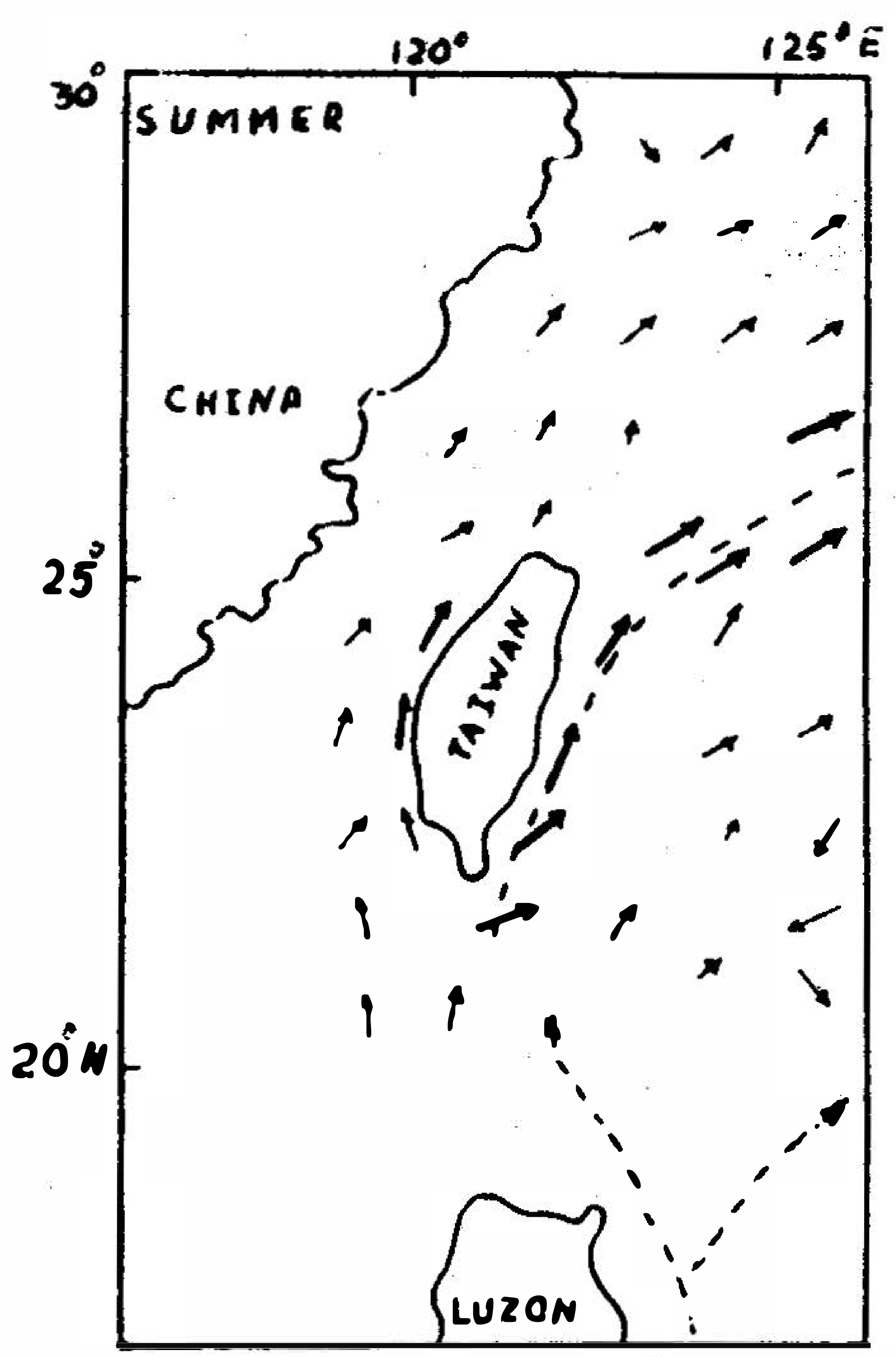

(a)

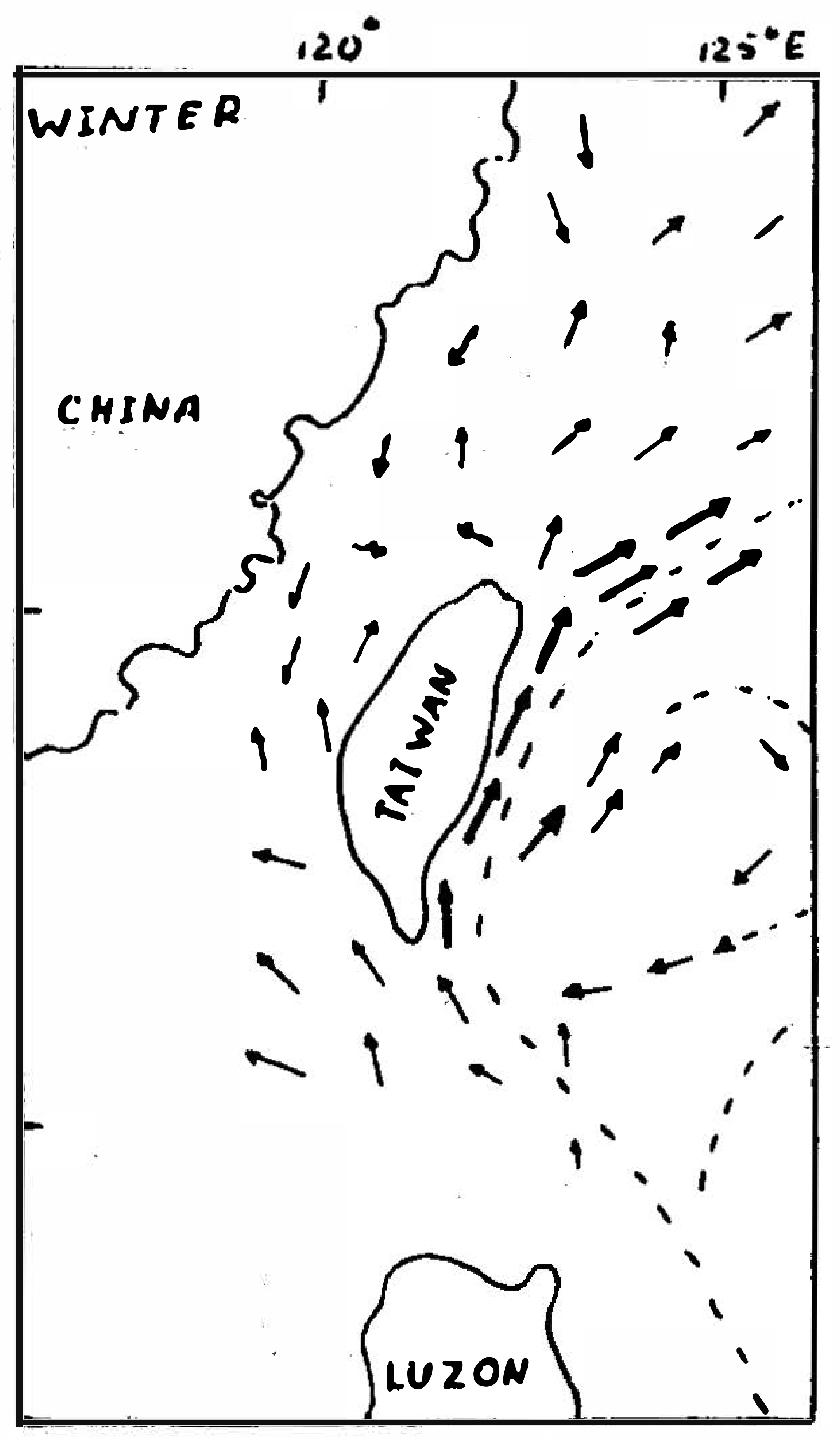

(b)

Fig. 4. The schematic of surface water circulation around Taiwan in summer (a) and winter (b) seasons developed by Stommel and Ioshida (taken from Fan, 1984)

center of the anticyclonic meander (station 6), the high potassium concentration core (up to $0.405 \mathrm{~g} / \mathrm{kg}$ ) roughly coincides with the layer of undersurface salinity maximum as well as the area of intermediate salinity minimum (Figures 5a, b). At this station, the intermediate salinity minimum is represented by a thin layer with the potassium concentration of 0.4026 $\mathrm{g} / \mathrm{kg}$ at the depths of 700 800 m, under which at the depth of $1400 \mathrm{~m}$ another potassium maximum is registered (Figure 5b). For waters not involved with the meandering (station $3 \mathrm{~A}$ belonging to the coastal branch of the Kuroshio, for example), the undersurface maximum and intermediate minimum of salinity agree with those for potassium (Figures $5 \mathrm{a}, \mathrm{b}$ ). Thus, one can assume that a deformation of the potassium field corresponding to the field of salinity at station 6 is caused by the meandering of the offshore Kuroshio branch. The active circulation at the depths of station 6 (Figure 2) suggests that both potassium maxima are related to the circulation fields.

The East-of-Taiwan division of the Kuroshio into branches is supported by salinity and potassium distributions registered at the section along $122^{\circ} \mathrm{E}$ (Figures $6 \mathrm{a}, \mathrm{b}$ ). The existence of two isolated cores with high potassium concentrations in the layer of the undersurface salinity maximum and those two with low potassium concentrations in the layer of the intermediate salinity minimum of the tropical water structure could be used as indirect tracers of the Kuroshio branches. As the position of potassium isolines depends upon water movement, eddies observed at stations 13,15,.17 (Figure 1) are to be confirmed by potassium distribution, to be both anticyclonic and cyclonic. The interaction of the anticyclonic and the cyclonic fornations leads to upwelling at station 14 and downwelling at station 15 (Figure 6b). 

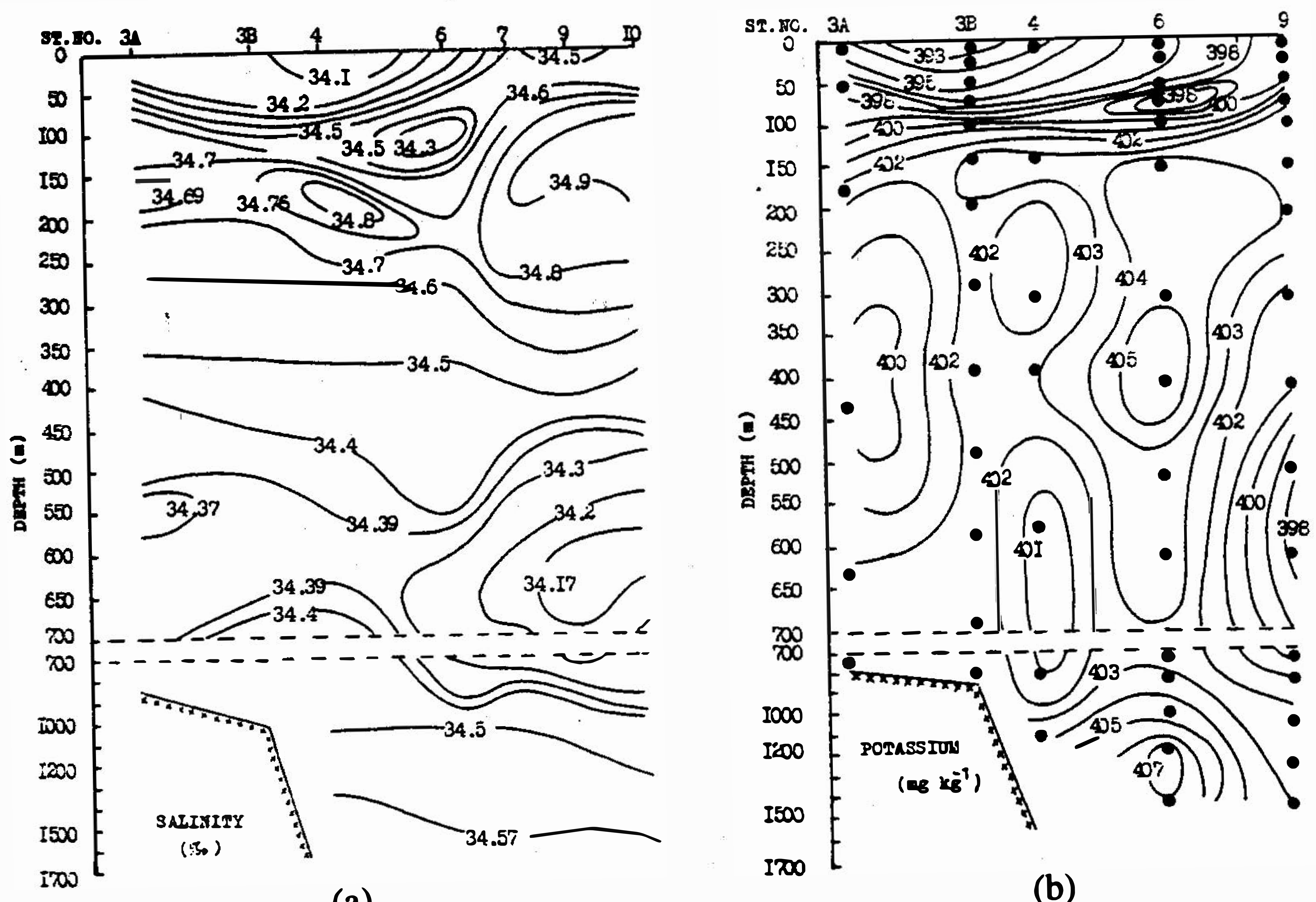

(a)

(b)

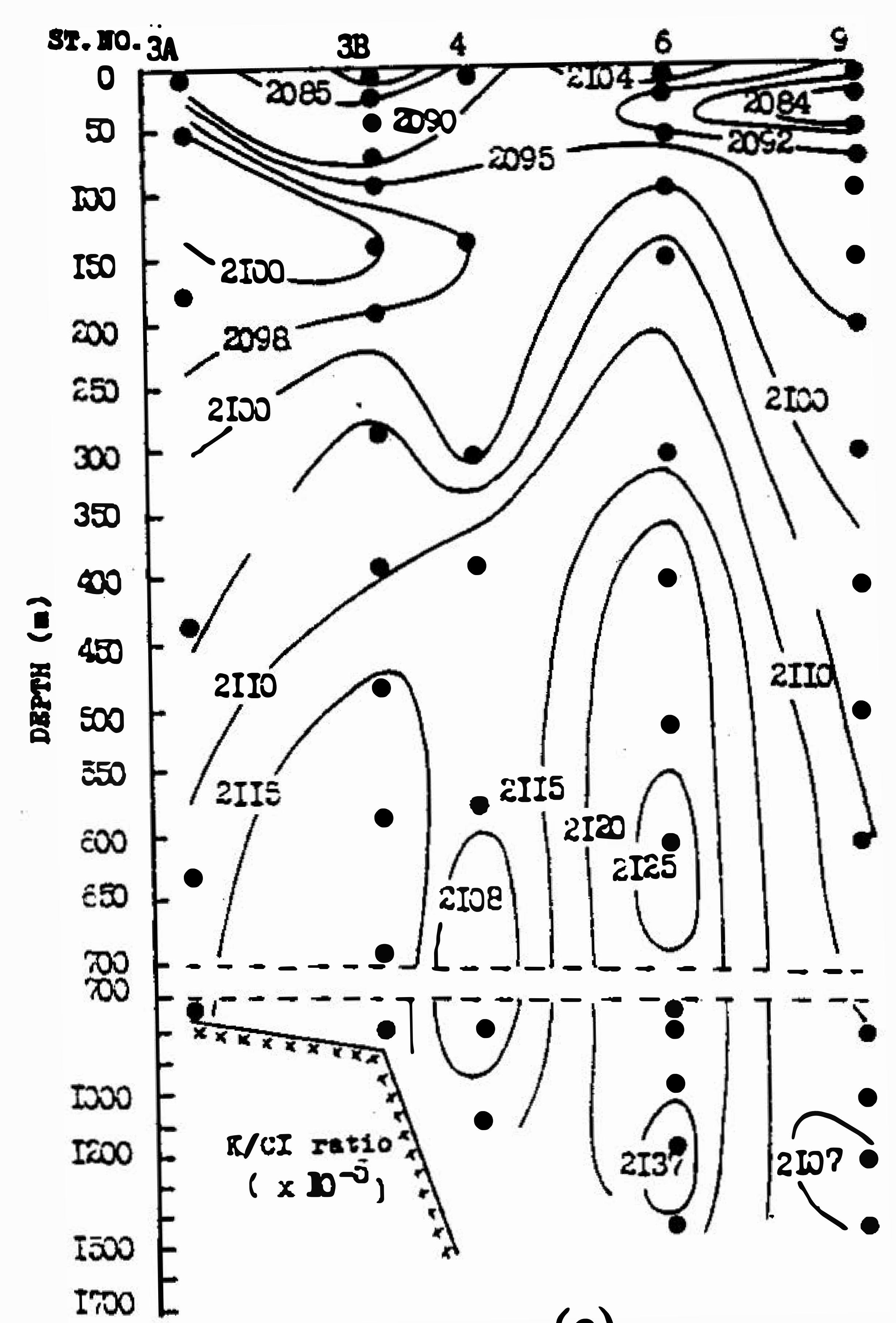

(c)

Fig. 5. The vertical distribution of salinity (a), potassium (b) and the $\mathrm{K} / \mathrm{CI}$ ratio (c) along $22^{\circ} \mathrm{N}$. 


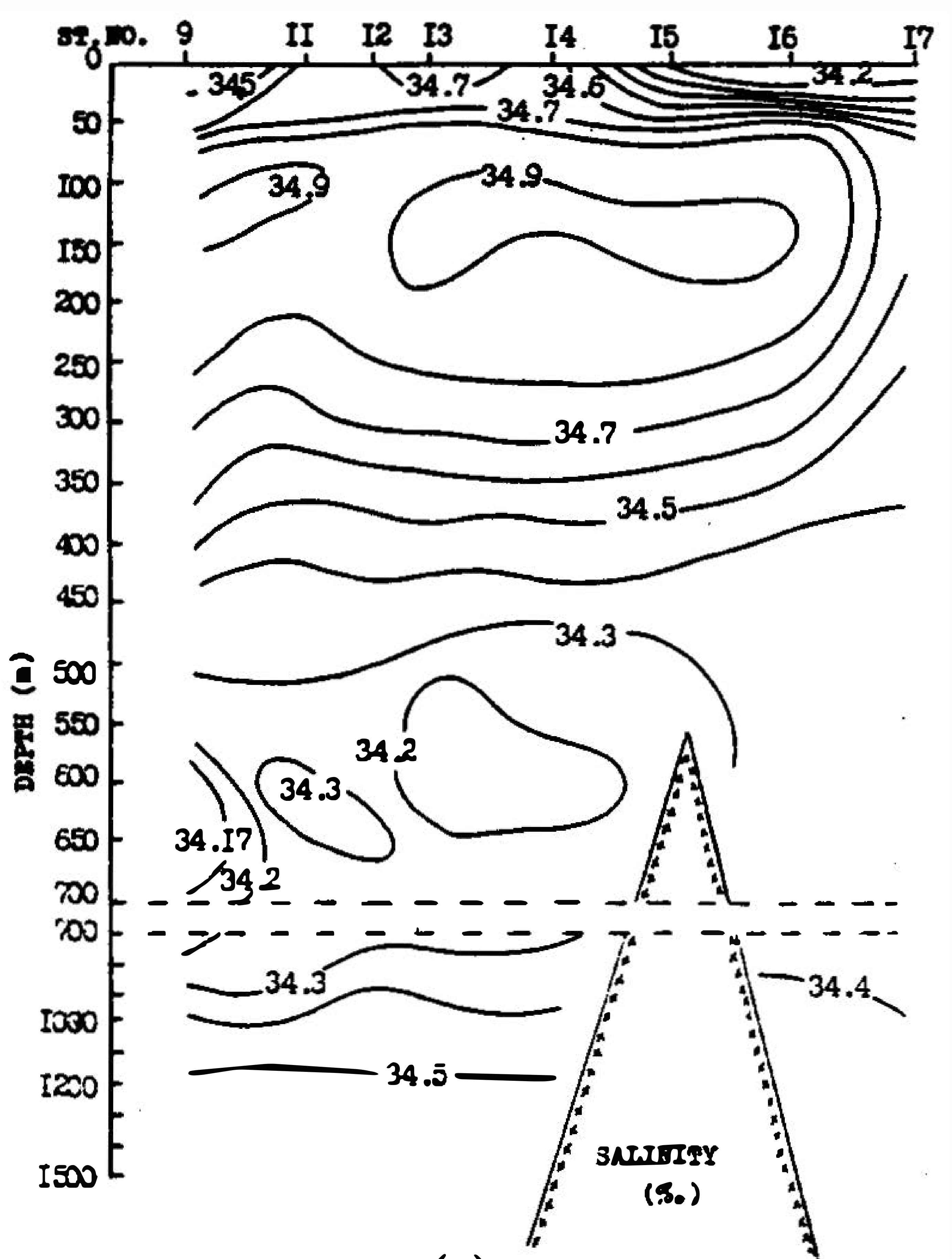

(a)
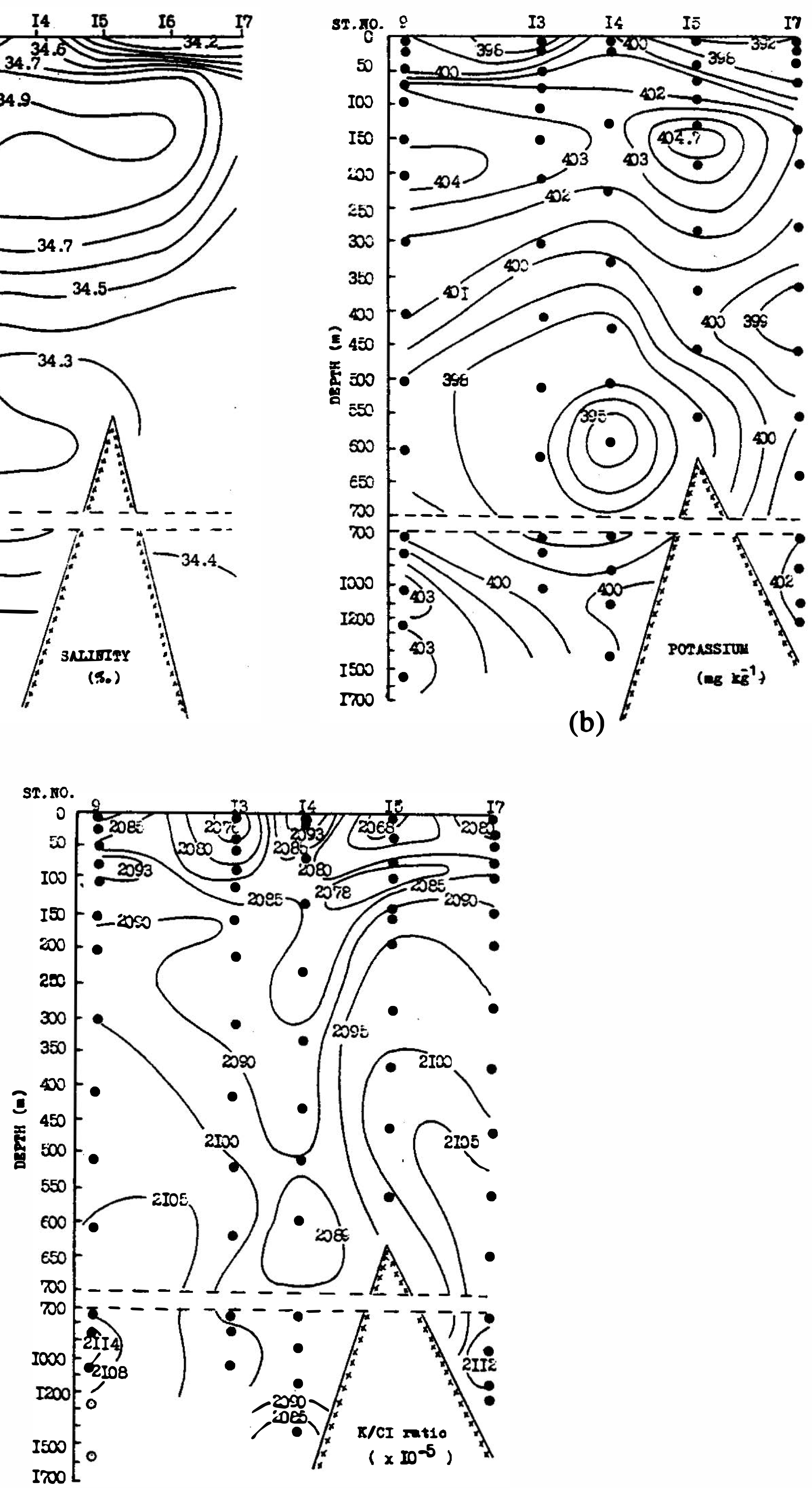

(c)

Fig. 6. The vertical distribution of salinity (a), potassium (b) and the $\mathrm{K} / \mathrm{CI}$ ratio (c) along $122^{\circ} \mathrm{E}$. 
Spatial variations of the $\mathrm{K} / \mathrm{Cl}$ ratio also reflect the water circulation characteristics in the study area. The $\mathrm{K} / \mathrm{Cl}$ ratio registered on the latitudinal section changes from 0.02082 to 0.02137 (Figure 5c) and on the longitudinal one - from 0.02069 to 0.02114 (Figure 6c). On the meridional section the isolated $\mathrm{K} / \mathrm{Cl}$ areas in the surface layer correspond to the centers of eddy-formations. The minimum $\mathrm{K} / \mathrm{Cl}$ ratio of 0.02068 was determined in the anticyclonic eddy at station 15 and the maximum value -0.02080 was found in the cyclonic eddies at stations 13 and 17 (Figure $6 \mathrm{c}$ ). It should also be pointed out that the high $\mathrm{K} / \mathrm{Cl}=0.02125$ is registered in the layer of the intermediate salinity minimum at station 6 (Figure 5a, c) while the low ratios of 0.02078 and 0.02090 are revealed in the layer of the undersurface salinity maximum at stations 15 and 13 (Figure 6a, c). Such "anomalous" values can be explained by vertical water movements inside the eddies. These movements result in the capture of either upper- or lower- layer concentrations and thus, may produce "anomalous" $\mathrm{K} / \mathrm{Cl}$ ratios. The waters outside the eddies are characterized by a relatively stable stratification of $\mathrm{K} / \mathrm{Cl}$. The following data better illustrate this point. The coastal Kuroshio branch actually has the same $\mathrm{K} / \mathrm{Cl}$ values at its beginning near the southern extreme of Taiwan Island (station 3B) and at the point where the Kuroshio enters the Okinawa Trough (station 17): 0.02082 and 0.02081 respectively (Figures $5 c$ and 6c).

\section{CONCLUSIONS}

The dynamic calculation, performed in this study suggests that in the area to the east of Taiwan, the Kuroshio current is represented by two branches. One narrow branch flows north-west along the eastern coast of the island and is characterized by a high velocity and a number of eddy-formations within the Nansei Rise region. The other branch separates from the coastal one near Lanhsu Island and forms anticyclonic and cyclonic meanders to the south-east of Taiwan.

Having analyzed dynamic topography charts, TS diagrams and seafloor topography, the authors came to the conclusion that the eddies formed to the north-east of Taiwan are the product of the variable depth and non stationary nature of the Kuroshio stream and the meander formation is the result of the a partial blocking effect of the Nansei Isles. The data obtained for potassium and the $\mathrm{K} / \mathrm{Cl}$ ratio distribution indirectly confirm the water circulation features identified by dynamic calculations. The resulfing isolated $\mathrm{K} / \mathrm{Cl}$ ratio pools in the surface layer corresponds to the centers of observed eddy-formations. Moreover, the variations in the $\mathrm{K} / \mathrm{Cl}$ ratio indicate that anomalous values (the low $\mathrm{K} / \mathrm{Cl}$ ratio in the undersurface salinity maximum and the high $\mathrm{K} / \mathrm{Cl}$ ratio in the intermediate salinity minimum of the ropical water structure) may have been caused by vertical water movement inside eddies.

As potassium and $\mathrm{K} / \mathrm{Cl}$ ratio fields reflect the characteristics of circulation processes, these parameters could be used as additional important indicators to estimate the water regime in the study area. In conjuction with the hydrological characteristics, they provide a rather reliable picture of the water structure in the region. The meandering of the Kuroshio beginning to the east of Taiwan may contribute to a better understanding of well-known "anomalous" phenomena of the Kuroshio, such as the deviation of the Kuroshio axis, the occurrence of the prominent cyclonic meander to the south of Japan and eddies formation in the Philippine Sea.

Acknowledgements The authors thank the captain and crew of the $R / V$ "Akademik Alexandr Vinogradov" for their assistance at sea and Mrs. Elena Koltunova for her help in the translation of this paper. 


\section{REFERENCES}

Chen, M. P., and A. Bychkov (Eds.), 1992: ROC-Russia Marine Science Collaboration Project: KEEPMASS Initial Data Report. Taipei, 450pp.

Cheney, R. E., 1977: Synoptic observations of the oceanic frontal system east off Japan. $J$. Geophys. Res., 82, 5459-5468.

Chem, C.-S., J. Wang, and D.-P. Wang, 1990: The exchange of the Kuroshio and East China Sea shelf water. J. Geophys. Res., 95, 16017-16023.

Chuang, W. S., H. W. Li, T. Y. Tang, and C. K. Wu, 1993: Observations of the countercurrent on the inshore side of the Kuroshio northeast of Taiwan. J. Oceanogr. Soc. Japan., 49, 581-592.

Defant, A., 1961: Physical Oceanography, Pergamon Press, New York, 1, 729pp.

Fan, K.-L., 1979: On upwelling along the southeastern coast of Taiwan. Acta Oceanogr. Taiwanica, 10, 151-159.

Fan, K.-L., 1980: On the upwelling of the northeastern shore of Taiwan. Acta Oceanogr. Taiwanica, 11, 105-117.

Fan, K.-L., 1982: A study of water masses in the Taiwan Strait. Acta Oceanogr. Taiwanica, $13,140-153$.

Fan, K.-L., 1984: The Branch of the Kuroshio in the Taiwan Strait. In: T. Ichiye (Ed.), Ocean Hydrodynamics of the Japan and East China Seas. Elsever Oceanography Series, Amsterdam, 77-82.

Fan, K.-L., and C.-Y. Yu, 1981: A study of water masses in the seas of southem Taiwan. Acta Oceanogr. Taiwanica, 12, 94-111.

Hsueh, Y., J. Wang, and C.-S.Chem, 1992: The intrusion of the Kuroshio across the continental shelf northeast of Taiwan. J. Geophys. Res., 97, 14323-14330.

Huppert, N. E., and K. Bryan, 1976: Topographically generated eddies. Deep-Sea Res., 23, 655-679.

Ichiye, T., 1955: On the behaviour of the vortex in the Polar Front Region. Oceanogr. Mag., 7, 115-132.

Ichiye, T., and C. Ichiye, 1956: The change of various kinds of vortices in the sea east of the Honshu. Oceanogr. Mag., 8, 123-141.

Isaeva, A. A, V. K. Savchenko, and V. N. Soifer, 1986: Shipboard express-method for potassium determination in seawater. VINITI Series, Moscow, No.5623-B86, 23pp (in Russian).

Kawai, H., 1972: Hydrography of the Kuroshio Extension. In: H. Stommel and K. Yoshida (Eds.), The Kuroshio: Its Physical Aspects, Univ. of Washington, Seattle, 235-352.

Kitani,K., 1975: Some properties of the warn eddies generated in the confluence zone of the Kuroshio and Oyashio currents. J. Phys. Oceanogr., 15, 245-252.

Masuzawa, I., 1955: An Outline of the Kuroshio in the Eastern Sea of Japan. Oceanogr. Mag., 7, 29-47. 
Masuzawa, I., 1957: An example of cold eddies south of the Kuroshio. Res. Oceanogr. Works of Japan, 13, 1-7.

Midgley, D., and K. Torrance, 1978: Potentiometric Water Analysis, Central Electricity Research Lab., Leatherhead, England, 516pp.

Nitani, H., 1972: Beginning of the Kuroshio. Kuroshio. In: H. Stommel and K. Yoshida (Eds.), Its Physical Aspects Univ. of Washington, Seattle, 129-163.

Nishiyama, K., S. Konaga, and H. Ishizaki, 1980: The cold water eddy observed south of Shikoku in September 1979. Oceanogr. Mag., 31, 27-32.

Qiu, B., J. Toda, and N. Imasato, 1990: On the Kuroshio Front fluctuations in the East China Sea using satellite and in situ observational data. J. Geophys. Res., 95, 18191-18204.

Savchenko, V. K., A. A. Isayeva., V. N. Soifer, and V. I. Ilyichev, 1988: Reports USSR Acad. Sci., 300, 74-79.

Su, J., and Y. Pan, 1988: On the shelf circulation north of Taiwan. Acta Oceanogr. Taiwanica, 21, 1-17.

Stalcup, M. C., 1991: Salinity measurements. WOCE Operation Manual. WHP Operations and Methods. WOCE Report No.68/91, 1-17.

Sugimoto, T., S. Kimura, and K. Miyaji, 1988: Meander of the Kuroshio Front and current variability in the East China Sea. J. Oceanogr. Soc. Japan, 44, 125-135. 
